\title{
Research on the Impact of External Situation on Power Grid Project Investment
}

\author{
CHAI Yufeng ${ }^{1, \mathrm{a}, *}$, TIAN Xin ${ }^{1, \mathrm{~b}}$ and JIN Xiaoling ${ }^{1}$ \\ ${ }^{1}$ State Grid Energy Research Institute Co., LTD, Beijing, 102209
}

\begin{abstract}
In recent years, China sees complicated and volatile external situation and growing downward pressure on the domestic economy. Moreover, COVID-19 has adversely affected China's economic and social development. In such context, the Company, as the great strength and strong pillar, reduces the energy consumption cost for three consecutive years. Besides, uncertain factors in terms of power grid development investment have brought about larger impact on the demand and capacity of power grid project investment and proposed higher requirements on the Company. Externally, economic and social development, national strategic deployment, implementation of power supply planning and planned load, and trans-provincial and trans-regional power trading mechanism have a crucial impact on the actual operating benefits of power grid projects.
\end{abstract}

\section{Introduction}

The Company, as a key state-owned backbone enterprise that has a vital bearing on the lifeline of the national economy and the national energy security, is essential to social stability and people's wellbeing. Its investment remains at a high level. Since the 13th Five-Year Plan, the Company has seen an annual investment of over RMB500 billion, reaching $25 \%$ of the total investment of central enterprises in the state-owned assets system, which is higher than the total annual investment of the five major power generation enterprises. It outperforms the international public utilities in terms of investment scale, volume, number of projects and social responsibilities undertaken. In the coming period, the Company will make efforts to enhance the transformation and upgrading of power grid and improve its safety, quality, efficiency, benefits and services so as to maintain the power grid investment at a historical high level and promote it to grow. Moreover, it needs to step up its customer service capability. The Central Economic Work Conference proposed to further optimize the business environment and continuously improve the ranking of China's "getting electricity" index. Meanwhile, with the deepening of the reform of the power system, social capital actively participates in the retail electricity market competition. In light of significant changes in the business environment, the Company should make greater efforts to build a modern service system, optimize the management process, quickly respond to market changes, play the supporting role of the power grid foundation, and do a good job in high-quality power supply services.

\section{Analysis of external situation affecting power grid project investment}

In recent years, the complicated and volatile external situation in China has given rise to increasing uncertainties in power grid development investment, exerted a greater impact on the demand and capacity of power grid engineering investment and put forward higher requirements.

\subsection{Economic and social development}

China's economy has entered a stage of high-quality development and the industrial structure has been continuously optimized and adjusted. Affected by the pandemic, the growth rate of energy and power demand has dropped significantly, the uncertainty of power consumption growth has increased, and the investment in power grid projects has been standardized.

\subsubsection{Macroeconomic industrial environment}

In recent years, China's economic and social development has entered a new normal. Hindered by the weakening internal and external demands, the economy is facing downward pressure, the development mode has shifted from extensive growth based on scale expansion to highquality and efficiency growth, and the industrial structure has been continuously optimized and adjusted. Additionally, a large number of market players featuring expanding scale and increasing proportion in the tertiary industry have sprung out, thus driving economic growth. Since this year, COVID-19, coupled with the tension

\footnotetext{
aEmail: chaiyufeng@sgeri.sgcc.com.cn, ${ }^{b}$ email: tianxin@sgeri.sgcc.com.cn

*Corresponding author: chaiyufeng@sgeri.sgcc.com.cn
} 
between China and the United States, hindered the overall development of the domestic economy.

As of the first quarter of 2020, domestic GDP fell 6.8\% year-on-year, showing negative growth, with primary, secondary and tertiary industries dropping $3.2 \%, 9.6 \%$ and $5.2 \%$ year-on-year. With the introduction of strong macro- control policies by the state and the phased victory in the prevention and control of the pandemic, China's economy is expected to continue to pick up and improve in the next stage, with the overall economic growth showing a "V" shape.

Table 1 GDP Growth Rate Year on Year

\begin{tabular}{|c|c|c|c|c|}
\multicolumn{7}{|c|}{ Unit: \% } \\
\hline Year & Q1 & Q2 & Q3 & Q4 \\
\hline 2015 & 7.1 & 7.1 & 7.0 & 6.9 \\
\hline 2016 & 6.9 & 6.8 & 6.8 & 6.9 \\
\hline 2017 & 7.0 & 7.0 & 6.9 & 6.8 \\
\hline 2018 & 6.9 & 6.9 & 6.7 & 6.5 \\
\hline 2019 & 6.4 & 6.2 & 6.0 & 6.0 \\
\hline 2020 & -6.8 & 3.2 & 4.9 & -- \\
\hline
\end{tabular}

\subsubsection{Power consumption in the whole country}

As the basic industry of the national economy, electricity has become a barometer mirroring the national economy. The recent years have seen stagnant economic growth, significant decline in energy and power demands, and uncertain power consumption growth. In 2019, the power consumption of the whole society was 7225.5 billion $\mathrm{kWh}$, up $4.5 \%$ year-on-year, with the growth rate dropping $3.9 \%$ over the previous year. In 2018, the power consumption increased by $8.4 \%$ year on year, with the growth rate rising 1.8 percentage points over the previous year, reaching a new high since 2012 .

\subsubsection{Reduce the energy consumption cost}

Reducing electricity prices for general industrial and commercial businesses is a policy measure that China has continuously promoted in recent years to optimize the business environment and reduce energy consumption costs. Such policy has enhanced the Company's revenue and profit model, promoted scientific and accurate investment, and optimized the investment structure of the Company.

In 2018, the State Grid beat the full-year target of reducing electricity prices for general industrial and commercial businesses by $10 \%$ and reducing electricity consumption cost of customers by RMB91.5 billion. By 2019 , it completed the task of reducing electricity prices for general industrial and commercial businesses by another $10 \%$ and reducing electricity consumption cost of customers by RMB64.1 billion. The total reduction in two years reached RMB155.6 billion. The State Grid redoubled its efforts to resolutely implement the central government's price reduction and shouldered the responsibility of reducing energy consumption costs, supporting the development of the real economy and promoting social investment. In this regard, the Company vigorously taps potential and increases efficiency, reduces costs and saves expenses, continuously improves development quality and efficiency, pays more attention to scientific and accurate investment, and optimizes the investment structure.

\subsection{National strategic deployment}

Efforts should be made to actively promote energy supply revolution and improve the capacity of the power grid to optimize resource allocation. On June 13, 2014, General Secretary Xi Jinping delivered an important speech at the 6th meeting of the Central Leading Group for Financial and Economic Affairs, stressing that "China should promote the energy consumption revolution, the energy supply revolution, the energy technology revolution and the energy system revolution, and strengthen international cooperation in all aspects to realize energy security under open conditions". This major strategy is of rich connotation and profound meaning. It is the most systematic and complete discussion on energy security strategy in the history of our party and mirrors a new height of theoretical innovation in China's energy strategy. Practice has proved that this strategy complies with China's national conditions, conforms to the trend of the times and follows the laws of energy. It is a vital embodiment and scientific application of $\mathrm{Xi}$ Jinping's socialism with Chinese characteristics in the energy field in the new era, and is the action program guiding China's energy transformation and development in the new era.

In view of clean and efficient utilization of coal and development of new energy sources, the Company has continuously increased its investment to promote the construction of ultra-high voltage and ultra-high voltage backbone networks and urban and rural distribution networks as a whole, and implement "diversion of electricity from the western to the eastern regions and supply of electricity for the north by the south regions", thus improving the grid-connected consumption capacity and power supply guarantee level of the power grid. The Company adheres to the concept of safe, high-quality, economic, green and efficient power grid development, strives to promote the high-quality development of the power grid, continuously improves the allocation capacity and intelligence level of energy resources, insists on innovation as the drive, persistently eliminates hidden 
dangers and prevents risks, improves the emergency response capacity, fully ensures the continuous and stable supply of power, and safeguard the stable operation of large power grids. By 2019, the Company built 50,701km the $110 \mathrm{kV}$ and above line with a capacity of 293.19 million $\mathrm{kVA}$. A total of $50,752 \mathrm{~km}$ with a capacity of 281.44 million kVA were put into operation, exceeding the annual construction task. The trans-regional and transprovincial transmission capacity reached 210 million $\mathrm{KW}$, and the cumulative UHV transmission capacity exceeded 1.6 trillion $\mathrm{kWh}$. By the end of 2019, the grid-connected capacity of new energy sources had reached 348.42 million KW, up $16.1 \%$ year on year. In 2019, new energy generation reached 601.818 billion $\mathrm{kWh}$, up $16.52 \%$ yearon-year, with a utilization rate of $96.8 \%$. The reliability of power supply in urban and rural areas has been significantly improved, providing a strong guarantee for economic and social development and improvement of people's livelihood.

Continue the three critical battles against poverty, pollution and major risks and accelerate the pace of power grid investment represented by UHV. The Company strictly controls the investment scale and invests valuable funds to help win the three critical battles and serve the country's major strategies. It has made significant progress in serving the strategy of poverty eradication and rural revitalization. Besides, the Company conscientiously implements the spirit of the No. 1 central document and deploy the full implementation of the rural electrification upgrading project. To increase investment in power grids in poor areas, the Company has made a total investment of RMB645.9 billion, including an investment of RMB160.4 billion in 2019, completing a new round of rural power grid renovation and upgrading tasks determined by the national plan one year ahead of schedule. In the past four years, the Company has built and renovated 109,000 km of $110 \mathrm{kV}$ and $35 \mathrm{kV}$ lines with a capacity of 210.34 million kVA. In 2019, it invested RMB4 billion in the gridconnected project of photovoltaic poverty alleviation projects. Up to now, the cumulative grid-connected capacity exceeds 19.42 million $\mathrm{KW}$, benefiting 2.78 million poor households. Moreover, the Company offered assistance to lift "four counties and one district" in Hubei and Qinghai out of poverty or helped them to reach the national poverty line within the year. Each unit of the Company has helped to lift 1,544 poverty alleviation points and 330,000 poor people out of poverty. Remarkable results have been achieved in helping win the battle against pollution. In addition, the Company increased investment in power grid construction, completed a number of new energy transmission and consumption projects such as $750 \mathrm{kV}$ three channels in Gansu, and promoted the development of new energy. The grid-connected capacity of new energy in the operating area increased by $14 \%$ year-on-year, the power generation increased by $15 \%$ year-on-year, and the utilization rate of new energy reached $96.7 \%$, reaching over $95 \%$ of the target one year ahead of schedule.

On May 29, 2020, the Qinghai-Henan $\pm 800 \mathrm{kV}$ highvoltage transmission line (Gansu section) was completed. The Qinghai-Henan Project is a national key project to implement the important instructions of General Secretary
Xi Jinping during his visit to Qinghai, to practice the concept of green development, to support the old revolutionary base areas in overcoming poverty, to resolutely win the battle against poverty, and to promote economic and social development. It is also a major innovation in China's development and application of UHV transmission technology to promote the large-scale development and utilization of new energy sources, which will further improve the safety, reliability and standardization level of UHV transmission. As the world's first UHV transmission channel featuring all clean energy, the project starts at Hainan Converter Station in Hainan Prefecture of Qinghai Province and ends at Zhumadian Converter Station in Zhumadian City of Henan Province. It passes through Qinghai, Gansu, Shaanxi and Henan provinces, with a transmission distance of $1587 \mathrm{~km}$ and a total investment of RMB22.6 billion. Among them, the Gansu section of the line starts at the junction of Qinghai and Gansu, with a length of $439 \mathrm{~km}$ and 794 towers. The completion of the project will effectively improve the overall level of clean energy delivery and consumption in most parts of Qinghai and Gansu, which is of great significance for ensuring national energy security, promoting clean development, stimulating economic growth, winning the battle against poverty and defending the blue sky.

The year 2020 is a decisive year to win the battle and shake off poverty and also the concluding year for building a well-off society in an all-round way. In the context of the COVID-19 and the downward pressure on the economy, the meeting of the Standing Committee of the Political Bureau of the Central Committee held on March 4 studied the current key work of pandemic prevention and control and economic and social operation and stressed that the construction progress of new infrastructures such as $5 \mathrm{G}$ network and data center should be accelerated. Undoubtedly, the "new infrastructure" has become the focus for the country to revitalize the economy and ensure the development of people's livelihood. As a central enterprise dedicated to public utilities, the Company, on the basis of "making sure stability in 6 key areas", pays special attention to stable growth and continuous innovation, and plays a vital role in promoting the transformation and upgrading of the power industry, boosting the new economic growth drivers, and meeting the needs of the people for a better life. Company leaders attach great importance to the "new infrastructure" work. This year, all power transmission and transformation projects of $35 \mathrm{kV}$ and above and pumped storage projects under construction will resume work and production. It is estimated that the total investment in construction projects this year will be RMB181.1 billion, driving a social investment of RMB360 billion and rendering a total scale of RMB541.1 billion. As a comprehensive platform featuring a wide service range, strong optimal configuration capability, high safety and reliability, green and low carbon, UHV has played and will continue to play an important role in promoting the revolution in energy production and consumption, realizing clean substitution and electricity substitution, vigorously stimulating upstream and downstream enterprises such as power supply, electrical equipment, energy-using equipment and 
raw materials to resume work and production, releasing more multiplier effects, injecting strong impetus into economic and social development, improving the power supply guarantee capacity for people's livelihood, and helping win the three critical battles.

It is necessary to implement the renewable energy quota system policy and propose urgent needs to speed up investment in the construction of clean energy transmission channels. In May 2019, the Notice of the National Development and Reform Commission and the National Energy Administration on Establishing and Perfecting the Guarantee Mechanism for Renewable Energy Electricity Consumption was issued, marking the official introduction of the renewable energy quota system policy and its formal implementation in 2020. The Notice proposes to establish and improve the guarantee mechanism for renewable energy electricity consumption, with the priority to determine the proportion target of renewable energy electricity in electricity consumption in each provincial region, namely "the responsibility weight of renewable energy electricity consumption". The weight of renewable electricity consumption responsibilities in each provincial region comprehensively takes into account factors such as renewable energy resources in each province (autonomous region and municipality directly under the Central Government), the total amount of electricity consumed by the whole society, the national energy plan and annual plan, the construction of major renewable energy bases, and the resource allocation capacity of trans-provincial and trans-regional transmission channels. Currently, in areas rich in wind, photovoltaic and water resources such as southwest, northwest and central China, the construction of power transmission channels and grid structures is lagging behind, and the consumption of renewable energy is still facing bottlenecks. By the end of 2019, the Jiuquan-Hunan $\pm 800 \mathrm{kV} \mathrm{HVDC}$ project has not been completed due to the UHV AC ring network in central China, which has led to the failure of timely decentralization and consumption of electricity at the receiving end, affecting the consumption and transmission of wind power and photovoltaic clean energy in Jiuquan area. In light of the reverse distribution of China's energy resource bases and load centers, to actively implement the national renewable energy quota system policy, an urgent need is put forward to speed up the construction of clean energy transmission channels and realize the optimal allocation of energy resources in a wider range.

\subsection{Power supply planning and construction}

Efforts should be made to promote coordinated regional development and enhance the construction of safe and efficient energy transmission channels. The report of the 19th National Congress of the Communist Party of China puts forward the implementation of the strategy of coordinated regional development, which has given new requirements and connotations to the opening-up of the western region, the revitalization of the northeast, the rise of the central region and the development of the eastern region. On this basis, the "Belt and Road" initiative, the coordinated development of the Beijing-Tianjin-Hebei region, and the construction of the Yangtze River Economic Belt are put forward. The coordinated regional development strategy provides a policy platform for exploring and building a modern energy system and becomes the driving force for accelerating the transformation of energy. Additionally, one of the important connotations of building a modern energy system is to continuously improve the cleanliness of energy supply. At present, clean energy consumption in China shows the obvious characteristic of concentrated distribution in regions and time periods. Among them, wind and photovoltaic energy curtailment are mainly concentrated in Xinjiang, Gansu, Inner Mongolia and other regions, mostly occurring during the winter heating period and night load valley period. In 2019, the above three provinces and autonomous regions have achieved a drop in both the rates of wind and photovoltaic energy curtailment. The average wind curtailment rate was $4 \%$, a year-on-year drop of 3 percentage points; the photovoltaic curtailment rate was $2 \%$, down 1 percentage point from the same period of last year. However, the proportion of wind and photovoltaic energy curtailment in the total amount of wind and photovoltaic energy curtailment in the country exceeded $81 \%$ and $87 \%$. The main reasons for wind and photovoltaic energy curtailment were the high proportion of new energy installed capacity, the large installed scale of thermoelectric units and self-owned power plants, the high system peak shaving pressure, and the limited transmission of new energy due to insufficient transmission capacity of some UHV channels. Water curtailment is mainly concentrated in Sichuan and Yunnan regions in the southwest, mostly occurring in flood season. The main reason for water curtailment is the large scale of hydropower construction, which requires large-scale trans-provincial transportation and consumption.

Measures should be taken to strengthen the allocation of power resources, enhance infrastructure construction such as power grid interconnection and transmission channels, and take solid steps to support the coordinated regional development strategy. In 2019, the Company implemented the strategy of developing the western region, revitalizing the northeast and spurring the rise of the central region. It promoted the construction of another "power road" for the full interconnection of Tibet's power grid, the Ali interconnection project, with a total investment of RMB7.4 billion and a total transmission line length of $1,689 \mathrm{~km}$. The project is scheduled to be put into operation in June 2021, which will completely end the history of the isolated operation of Ali Power Grid. In order to support the clean development of Qinghai, the Company has issued White Paper 2019 on Clean Energy Development in Qinghai. In the nine years from 2010 to 2018, the Company, with the aim of serving the consumption of clean energy in Qinghai Province, has invested in 26 clean energy transmission projects and 11 transmission channel projects, with a cumulative total investment of RMB16.4 billion, accounting for more than $30 \%$ of the total power grid investment. In addition, the Company has built a clean energy power grid project and completed a $750 \mathrm{kV}$ power transmission and transformation project in Xiangjia, completed $330 \mathrm{kV}$ new 
energy supporting power grids and collection and transmission projects such as Dagele, Golmud South and Xinlu Duoneng to meet the demand for clean energy collection and transmission in the whole province. Besides, the Company continued to improve the balance and regulation capacity of the power grid, strengthened the unified dispatching of the whole network, optimized the multi-energy complementary and coordinated control technology, explored the peak regulation potential of thermal power, enhanced the mutual aid of peak regulation of inter-provincial power grids, realized the "Green Power Nine Days" and fully absorbed clean energy. During the "Green Power Nine Days" period, the province generated 2.095 billion $\mathrm{kWh}$ of electricity and 2.031 billion $\mathrm{kWh}$ of clean energy (including 1.612 billion $\mathrm{kWh}$ of hydropower, 96 million $\mathrm{kWh}$ of wind power and 323 million $\mathrm{kWh}$ of solar energy). The province's cumulative electricity consumption was 1.76 billion $\mathrm{kWh}$, all provided by clean energy.

Moreover, the Company has made efforts to ensure the power supply of load centers in the Beijing-Tianjin-Hebei region, Yangtze River Delta and central region, to serve the ecological protection and clean development of the Yangtze River and Yellow River basins, to promote Zhangbei-Xiong'an UHV AC, Yazhong-Jiangxi, Northern Shaanxi-Hubei and Baihetan-Jiangsu.

\section{Conclusions}

The efficiency and benefit of power grid project investment are affected by economic and social development, national strategic deployment, network source planning and coordination, etc. China's economy has entered a stage of high-quality development and the industrial structure has been continuously optimized and adjusted. Affected by the pandemic, the growth rate of energy and power demand has dropped significantly, the uncertainty of power consumption growth has increased, and the investment in power grid projects has been standardized. In terms of the strategy of serving the country, the Company has actively promoted the energy supply revolution, continuously strengthened the power grid's ability to optimize the allocation of resources, strictly controlled the scale of investment, invested valuable funds to help win the three critical battles, served the country's major strategies, implemented the renewable energy quota system policy, and put forward urgent needs for accelerating investment in the construction of clean energy transmission channels. In terms of network-source planning and coordination, major power transmission and transformation projects are usually used to solve the problem of large-capacity long-distance transmission. The implementation of power supply planning will directly lead to an uncoordinated source-network and affect the utilization efficiency of corresponding power transmission projects. In terms of the implementation of the planning load, the load growth and layout are important reasons for the planning and construction of power transmission and transformation projects. However, in the actual situation, due to changes in the industrial planning of the local government, the layout of power users such as industrial parks originally planned to be built has changed, resulting in an overestimation of the load growth rate in planning and feasibility study and low actual load rate of power grids, thus affecting the utilization efficiency of power transmission and transformation projects. In terms of electricity trading mechanisms, in the context of the continuous reform of trading centers set up by joint-stock system in China, the enterprise nature of power trading centers may be further extended. Power users can directly trade with power generation enterprises through transregional transmission channels on a large scale, which will improve the utilization efficiency of trans-regional transmission channels and increase the proportion of clean energy consumption.

\section{Acknowledgments}

This paper was supported by State Grid Corporation of China: Study on key technology for adapting to the company's strategic new system development investment for fine control, optimization and improvement (project code: 1300-201957273A-0-0-00).

\section{References}

1. Environmental Impact Post-Assessment of Dam and Reservoir Projects: A Review [J]. Q.G. Wang,Y.H. $\mathrm{Du}, \mathrm{Y}$. Su,K.Q. Chen. Procedia Environmental Sciences . 2012

2. Energy saving effect prediction and post evaluation of air-conditioning system in public buildings [J]. Chenchen Chang,Jing Zhao,Neng Zhu. Energy \& Buildings . 2011 (11)

3. Influence of reference points in ex post evaluations of rail infrastructure projects [J].Transport Policy. 2010 (4)

4. Investment evaluation within project management: an information systems perspective $[J]$. Irani,Z. The Journal of the Operational Research Society. 2010 (6)

5. Research on practical power system stability analysis algorithm based on modified SVM. HOU Kaiyuan,SHAO Guanghui,WANG Haiming, et al. Protection and Control of Modern Power Systems . 2018

6. Network DEA Models for Evaluating Couriers and Messengers [J]. Ewa Chodakowska, Joanicjusz Nazarko. Procedia Engineering. 2017 